\title{
¿UNA ANTINOMIA CONSTITUCIONAL? EL SUFRAGIO (DES)IGUAL EN LA CONSTITUCIÓN DE 1978
}

\author{
JORGE URDÁNOZ GANUZA \\ Profesor Contratado Doctor de Filosofía del Derecho \\ Universidad Pública de Navarra
}

TRC, núm. 45, 2020, pp. 353-378

ISSN 1139-5583

\section{SUMARIO}

I. Del principio de igualdad al sufragio igual. II. Tres dimensiones del voto. III. Los tertia del sufragio igual. IV. Igualdad, proporcionalidad y la equivocidad alemana. V. El sufragio igual en el constitucionalismo comparado. VI. Paradojas, aporías, contradicciones. El sufragio igual en España.

\section{DEL PRINCIPIO DE IGUALDAD AL SUFRAGIO IGUAL.}

Es habitual iniciar el estudio de la cuestión del voto igual mediante consideraciones abstractas referidas al principio de igualdad. $\mathrm{Y}$ existe, con respecto a tal principio, una literatura casi inabarcable, en la que abundan distinciones teóricas destinadas a iluminar unos u otros aspectos incluidos bajo su amplísimo campo semántico. Aunque la enumeración de este tipo disecciones analíticas podría no tener fin, sí que parece tener un principio más o menos consensuado en Platón y Aristóteles. Es sabido que ambos vinieron a afirmar que hay que tratar de modo igual a lo que es igual y de modo diferente a lo que es diferente ${ }^{1}$, y que, al hacerlo, dieron origen a toda esta tradición discursiva en la que bullen, bajo el término «igualdad», ideales considerablemente distintos (la no discriminación, la justicia

1 La idea aparece expresada en Platón (Leyes, lib. VI, 757) y Aristóteles (Política, lib. II, 1280a, 1282b y 1283a; Etica a Nicómaco, lib. V, 1130-1133). Tomamos ambas citas de ReY F., «¿De qué hablamos cuando hablamos de igualdad constitucional?», Anales de la Cátedra Francisco Suárez, Vol. 45, 2011, p. 168.

UNED. Teoría y Realidad Constitucional, núm. 45, 2020, ISSN 1139-5583, pp. 353-378 
y la proporcionalidad, esencialmente) cuya mera delimitación conceptual dista de ser pacífica ${ }^{2}$.

Aquí, sin embargo, no vamos a seguir ese camino. O, más bien, vamos a posponerlo, iniciando el recorrido no tanto por las alturas de lo abstracto como por los más transitables senderos de lo concreto. Tomaremos como modelo a Alexy, para quien «hay que distinguir (en la constitución) entre un derecho general de igualdad y derechos especiales de igualdad ${ }^{3}$. El derecho general de igualdad es uno, y se establece en el artículo 3.1 de la Ley Fundamental de Alemania. Los derechos especiales de igualdad son varios. Alexy cita los estatuidos en los artículos 3.2 (igualdad entre hombres y mujeres), 3.3 (no discriminación), 6.5 (iguales derechos para los hijos nacidos dentro y fuera del matrimonio), 33.1 (igualdad de derechos entre los alemanes), 33.2 (igualdad de acceso a cargos públicos), 33.3 (igualdad religiosa) y, muy especialmente para lo que aquí nos interesa, el 38.1 (sufragio igual). Siendo ello así, cabe aplicar un paralelismo al respecto en nuestra constitución, en la que existirían, junto al derecho general de igualdad establecido en el 14, otros derechos especiales de igualdad: el del 23.2 (igualdad de acceso), el del 31.1 (igualdad y progresividad en los impuestos), el del 39.2, el del 139.1, el del $149.11 \mathrm{y}$, sin duda, el derecho al «sufragio igual» establecido en el 68.14.

Esta inclusión de la expresión «sufragio igual» en el articulado constitucional nos permite abandonar, siquiera momentáneamente, las sutilezas filosóficas sobre el principio de igualdad y abordar directamente la cuestión. Si la constitución garantiza a los ciudadanos españoles que su sufragio ha de ser «igual», ¿en qué exactamente ha de serlo? ¿A qué variable viene referida tal igualdad? Porque la igualdad es, en palabras de Rubio Llorente, un concepto relacional, esto es, necesita un «tertium» del que predicarse, de tal manera que sólo en comparación con el mismo pueda establecerse de dos elementos cualesquiera que

2 La distinción entre Igualdad formal y material es un clásico desde Heller. Alexy disecciona analíticamente el concepto y ofrece, entre otras, las siguientes categorías: igualdad en la aplicación y en la formulación del derecho; igualdad de hecho e igualdad de iure; derechos de igualdad prima facie y derechos de igualdad definitivos (que a su vez pueden ser tanto abstractos como concretos). Entre nosotros, Pérez Luño ha diferenciado entre la igualdad como valor, la igualdad como principio y la igualdad como derecho fundamental. Dworkin deslindó hace años la igualdad de impacto de la igualdad de influencia. Véase, respectivamente, HeLler H., «Las ideas socialistas», en: Escritos Políticos, Alianza, Madrid, 1985; Alexy R., Teoría de los derechos fundamentales, Centro de Estudios Políticos y Constitucionales, 1993; Pérez Luño A.E., «Sobre la igualdad en la Constitución española», Anuario de Filosofía del Derecho, 4, 1987; Dworkin R., Sovereign virtue: The theory and practice of equality, Harvard university press, 2002. Una excelente panorámica filosófico-política de las relaciones entre la idea de igualdad política y los métodos de decisión se encontrará en Ruiz Miguel A.: «La igualdad política», Derechos y libertades. Revista del Instituto Bartolomé de las Casas, nº 11, 2002.

3 Alexy R., op.cit, p. 381.

4 A juicio de Pérez Luño, nuestra constitución no sigue exactamente este modelo alemán - basado en «el principio de la igualdad formal» y «sus proyecciones subjetivas» - sino que procede más bien afirmando la no discriminación en el 14 y reconociendo luego «derechos fundamentales de igualdad en otros sectores del articulado», entre los que cita como ejemplos todos los que hemos referenciado, con excepción del sufragio igual del 68.1 que, a nuestro juicio, ha de ser citado igualmente con todo merecimiento. En Pérez LuÑo, op. cit., pp. 145-146. 
son, o no, iguales 5 . Es evidente que, si yo voto al Partido Amarillo, la Constitución no está diciendo que, puesto que sufragio de los españoles ha de ser igual, todos los españoles han de votar al Partido Amarillo para no violar así el contenido del 68.1. Es también evidente que, puesto que mi sufragio se emite en Pamplona, en la Mesa 9 del distrito 24, la constitución no está obligando al resto de mis conciudadanos a que voten en dicha mesa para que su sufragio sea igual al mío. Hay casi infinitos elementos o «tertia» a los que es inmediato que no se refiere la igualdad establecida en el 68.1: el contenido del sufragio, la hora en que se emite, el espacio físico en el lo hace, el peso y estatura de quién lo introduce en la urna, etc., etc., etc. No se trata, así, de eliminar las inúmeras posibilidades que no aclaran la cuestión, sino más bien de delimitar las escasas que sí: ¿A cuál o cuáles variables cabe establecer que viene referido el mandato constitucional del «sufragio igual»? Antes de abordar esa cuestión, sin embargo, habremos de profundizar en una previa: los diversos sentidos de la propia expresión «sufragio» ${ }^{6}$.

\section{TRES DIMENSIONES DEL VOTO}

En el interior de la expresión «voto» conviven al menos tres sentidos diferentes. El primero remite a una capacidad que alguien posee («fulano tiene un voto en en el comité»). El segundo hace referencia a una decisión ya tomada («fulano votó por el partido amarillo»). El primero es psicológico, abierto e interno; el segundo es físico, cerrado y externo. Podemos así diferenciar entre el voto como capacidad de decidir y el voto como decisión tomada. El primero es el voto en cuanto que poder, facultad o potencia que jurídicamente se otorga a cada ciudadano. El segundo es el resultado del ejercicio que cada ciudadano ha hecho de su voto-capacidad. Entre ambos sentidos se interpone, a la manera de un filo a la vez lógico y temporal que los separa de modo ontológicamente ineludible, un tercer sentido: el acto de la votación propiamente dicha («fulano ha introducido su voto en la urna»). La votación - en el caso español, las doce horas que transcurren entre las 8 de la mañana y las 8 de la tarde del día legalmente determinado por el $\mathrm{BOE}$ en la convocatoria electoral ${ }^{7}$ - separa en efecto el instante en el que el voto deja de ser capacidad potencial y pasa a ser decisión en acto. Una transformación que acontece con absoluta independencia de la voluntad $-\mathrm{o}$ ausencia de la misma- que al respecto albergue cada elector.

5 Rubio Llorente, F., «La igualdad en la jurisprudencia del Tribunal Constitucional», Revista Española de Derecho Constitucional, 31, 1991, p. 13.

6 Mientras no se diga lo contrario, los términos «voto» $\mathrm{y}$ «sufragio» son del todo intercambiables a los efectos del presente texto.

7 Ese lapso temporal puede ser diferente - por ejemplo en el caso del voto por correo o del voto para los residentes en el extranjero- pero existe siempre.

UNED. Teoría y Realidad Constitucional, núm. 45, 2020, ISSN 1139-5583, pp. 353-378 
Un ciudadano al que se le ha concedido en virtud del ordenamiento jurídico un voto-capacidad puede o bien votar o bien no votar. No hay más opciones, pero - esto es fundamental - ambas son siempre e indefectiblemente un voto-decisión. En este sentido analítico, por tanto, abstenerse es, en contradicción con el lenguaje natural, una forma de votar. Esto es, es una forma de usar, ejecutar o activar el voto capacidad. Y, de hecho, en efecto, de un elector que se abstiene solemos decir que decide abstenerse o que decide no votar, lo que a la postre vendría a ser equivalente a decir que «vota (psicológicamente) por no votar (procedimental o institucionalmente)».

Siendo ello así, al cerrarse las urnas no quedan ya votos-capacidad. Todos se han transformado en votos-decisión. Unos son voto abstenciones, esto es: son votos-decisión que han decidido no acercarse a las urnas. Otros son votos emitidos, esto es: son votos-decisión que han decidido acercarse a las urnas y votar nulo, blanco o válido. Todos son votos decisión, puesto que todos son una manera consciente de ejecutar la capacidad otorgada por el ordenamiento jurídico ${ }^{8}$.

En las elecciones generales de abril de 2019, por ejemplo, de los ciudadanos españoles censados en Valladolid, 80.148 decidieron abstenerse y 338.779 se acercaron a las urnas y emitieron un voto. De estos últimos, 2.791 votaron nulo, 3.724 votaron en blanco y 332.264 votaron correctamente a una lista de partido. Pues bien, en el lenguaje natural, la expresión «voto» tiende a asignarse casi en exclusiva a los votos emitidos (y especialmente a los válidos). En ese lenguaje lo otro no son «votos», son «abstenciones» (todo lo contrario a los votos, de hecho). Pero, si queremos hacer justicia a la expresión «voto igual», hemos que tener en cuenta la distinción señalada e ir un poco más allá de la terminología al uso, pues parece evidente que el voto, en cuanto capacidad, es algo que también los abstencionistas tienen (o tenían, más bien, antes del cierre de las urnas) .

Tenemos así tres sentidos de la expresión «voto». Si el voto ha de ser «igual», ¿a cuál de los tres sentidos viene referida esa igualdad? ¿O viene referida a los tres? Se trata de una cuestión compleja, que en el presente texto no podremos abordar. Aquí nos vamos a ceñir tan solo a la igualdad referida a la primera dimensión, la del voto en cuanto capacidad, a la que no parece discutible que sí viene referida la expresión «sufragio igual». Como veremos, en ella se centran los Tratados internacionales y la inmensa mayoría de las decisiones constitucionales comparadas. El análisis de la igualdad con respecto a las otras dos dimensiones

8 Resulta conceptualmente interesante el caso de un elector que ni siquiera sea consciente de que existe un proceso electoral convocado. En un caso tal, el término «decisión» no sería, en efecto, el adecuado para su abstención. Pero, aunque sociológica y políticamente se trata de una cuestión que reviste el mayor interés, puede ignorarse sin problemas a los efectos de la argumentación jurídica y moral que se desplegará aquí.

9 En el lenguaje jurídico, nuestro voto-capacidad se aproxima mucho a la expresión «sufragio activo». Pero, por razones de claridad expositiva, seguiremos utilizando voto-capacidad, ya que el «sufragio activo» se contrapone jurídicamente al «sufragio pasivo» y no es esa la contraposición conceptual que estamos intentando atrapar aquí. 
del voto queda para otra ocasión, por lo que a partir de ahora, mientras no se explicite lo contrario, entenderemos «sufragio» como «voto capacidad» ${ }^{10}$.

\section{LOS TERTIA DEL SUFRAGIO IGUAL}

Parece evidente que la igualdad de sufragio se refiere de modo primordial a la capacidad de impacto que cada voto puede ejercer en el resultado. Así, para cualesquiera dos de los participantes en la votación dicha capacidad ha de ser idéntica. La Teoría de las Votaciones utiliza la expresión anonimidad para referirse a esta propiedad ${ }^{11}$. Un sistema electoral es anónimo si garantiza que todos los

10 Lo que no significa que las otras dos dimensiones no jueguen también un papel fundamental con respecto a la igualdad del sufragio. Del voto en cuanto acto (tercer sentido), el propio Tribunal Constitucional ha establecido en su sentencia 24/ 1990 que la «simultaneidad», esto es, la igualdad con respecto al tertium «tiempo» (que la votación tenga lugar un mismo día, o más bien que tenga lugar de tal modo que nadie sepa el resultado que arrojan los votos ya emitidos con anterioridad) afecta a la igualdad de voto. V. al respecto Pérez Alberdi R., «Igualdad de sufragio y sistema electoral», Revista General De Derecho Constitucional, 26, 2018, notas 11 y 12 y URDÁNOZ GANUZA J., «Legislación electoral y posibilidades participativas», Oñati Socio-legal Series, v 7, n 5, 2017, p. 974. Sin salirnos de este tercer sentido, es evidente también que ha de garantizarse la igualdad con respecto al tertium «posibilidad fáctica de votar»: que nadie vea afectado su derecho a emitir su voto por trabas meramente físicas o administrativas. V. ArCE Jiménez C., «Derecho de sufragio, administración y principio de igualdad», Estudios de Deusto: revista de la Universidad de Deusto, 66, 2018; Alberdi, op. cit., nota 11 y MATEOS CRESPo J.L.M.: «La implantación del 'voto rogado' en España: el perjudicial límite a la participación electoral de los españoles residentes en el extranjero a punto de enmendarse», Teoría y Realidad Constitucional, 2019. Con respecto al voto en cuanto decisión (segundo sentido) Óscar Sánchez señala, con indudable acierto, que «la igualdad de sufragio (...) también significa una igualdad (...) en cuanto al sistema electoral aplicable a cada voto». En SÁnCHEZ MuÑoz Ó., «Sistema electoral y principio de igualdad de sufragio», en: Francesc Pau i Vall (coord.), Parlamento y sistema electoral. IV Jornadas de la Asociación Española de Letrados del Parlamento, Pamplona, Thomson Reuters Aranzadi, 1999, pp. 522 y 523. En el trasfondo de esta afirmación se ha de recordar que es habitual afirmar que en España existen varios «subsistemas» electorales, unos más proporcionales que otros. El voto sería así desigual en cada una de las circunscripciones no solo antes de las urnas, sino además después, pues el sistema electoral en el que se computa sería diferente en cada provincia. Se trata de una cuestión considerablemente compleja, que aquí orillaremos. La tesis de los diferentes subsistemas es sin duda cierta, pero parte de una mirada holística, generalista, abstracta. La Ciencia Política — y, con ella, el Derecho Constitucional - suele enfocar el problema en términos de proporcionalidad del sistema electoral de la circunscripción. Se trata de una perspectiva que se dirige hacia el todo (la proporcionalidad del sistema) y no tanto al sufragio como derecho del ciudadano concreto (el sufragio individual). También aquí creemos que la Teoría de las Votaciones — una disciplina de la que enseguida diremos algo - y su perspectiva analítica proporcionan al Derecho una mirada radicada en el individuo, y por eso considerablemente más idónea que la habitual de la Ciencia Política a la hora de abordar determinados derechos subjetivos o individuales.

11 La Teoría de las Votaciones es un área de conocimiento a medio camino entre las matemáticas, la economía y la teoría política que se ocupa de las propiedades de los diferentes sistemas de votación ideados para alcanzar decisiones colectivas. Frente a la Ciencia Política — con la que comparte numerosas zonas en común - se caracteriza por una perspectiva mucho más analítica y matemática. Puede decirse que la Teoría de las Votaciones estudia los sistemas de votación en un laboratorio puramente conceptual, mientras que la Ciencia Política lo hace en la realidad empírica representativa. Sus mayores puntales intelectuales son quizás Duncan Black y Kenneth Arrow. Una buena visión de conjunto de la misma puede encontrarse en BRAMS S.J., Mathematics and Democracy: Designing Better Voting and Fair-Division Procedures, Princeton University Press, Princeton, 2008 
electores son tratados simétricamente $\mathrm{o}$, si queremos, que son intercambiables ${ }^{12}$. Así, dados un escrutinio determinado y unos resultados arrojados por el sistema para el mismo, ha de cumplirse que, aunque cualesquiera votantes intercambien sus votos, el resultado no se modifica, puesto que los votos y su cantidad siguen siendo los mismos, y lo único que se ha modificado es la mera identidad de los votantes. Se trata, como se desprende, de la venda que la justicia lleva en los ojos (que la vuelve ciega y torna así a los ciudadanos iguales ante ella) aplicada a los sistemas electorales (que han de ser anónimos ante sus votantes para que sus votos sean, también, iguales). Hay dos grandes modos de lesionar tal igualdad de impacto en el voto capacidad.

\section{El número de votos}

Un primer modo consiste en dar a unos votantes más votos que a otros, una práctica cuya más célebre defensa filosófica se debe a John Stuart Mill. Parece obvio que la igualdad a la que se refiere el «sufragio igual» ha de garantizar sin objeción posible esta circunstancia: que todos los electores tengan un número de votos idéntico puesto que, en caso contrario, el impacto de la voluntad de unos en la decisión colectiva sería mayor (o menor, pero en todo caso desigual ${ }^{13}$.

\section{El valor del voto}

El segundo modo consiste en lograr que ciertos votos tengan adjudicado un valor mayor decisional que otros. El mejor ejemplo es el denominado «voto de calidad» que en ocasiones ciertos sistemas de votación otorgan al presidente de un comité en caso de empate. Estamos, de nuevo, ante una violación evidente de una propiedad que ha de estar protegida por la igualdad que se predica del sufragio. No solo ha de ocurrir que todos los electores tengan el mismo número de votos, sino que se ha de garantizar — por idéntica razón: para evitar que el impacto de unos en la decisión colectiva sea mayor (o menor) que el de otrosque cada voto tenga el mismo valor o, dicho de otro modo, que influya de una manera idéntica en el resultado final.

Hoy en día muchos sistemas electorales otorgan votos con valor diferente a sus electores. Lo habitual para ello es utilizar la existencia de «distritos» o «circunscripciones», sobre los que lo primero que conviene señalar es que en absoluto

12 MAY K.O., «A set of independent necessary and sufficient conditions for simple majority decision», Econometrica: Journal of the Econometric Society, 1952.

13 Una enumeración de las formas principales que adopta esta manera de desigualar el voto-capacidad se hallará en el Informe del Consejo de Estado sobre la reforma electoral: Texto del informe y debates académicos, Centro de Estudios Políticos y Constitucionales, Madrid, 2009, pp. 161-162. 
dividen — como se afirma de modo casi unánime - el territorio, sino la población. Una cosa es el criterio mediante el que se divide algo y otra es aquello que está siendo sometido a la propia división. Antes, en los parlamentos medievales, el criterio a la hora de dividir a la población era el Estamento. Otros criterios utilizados históricamente han sido el dinero, la profesión o el nivel de estudios. En la mayoría de los países - España entre ellos - hoy en día el criterio para dividir a la población es territorial, pero no es el territorio el que resulta dividido, sino los propios electores, que tras tal operación quedan repartidos en unos u otros conjuntos de personas.

Una vez que un sistema electoral divide a sus electores en diferentes grupos, puede otorgar a unos un sufragio más poderoso que a otros, simplemente concediéndoles a unos más escaños para elegir que a otros. Históricamente, este tipo de desigualdad en el valor de voto ha sido con mucho la más extendida y utilizada en los ordenamientos electorales. De hecho, era aquella contra la que, desde una perspectiva democrática, se dirigieron en primer lugar las exigencias de igualdad en el sufragio. La práctica puede retrotraerse hasta los sistemas representativos medievales, en los que, tal y como acabamos de mencionar, la sociedad se dividía en tres grandes adscripciones sociales o «Estamentos» (aristocracia, clero y pueblo llano). En el parlamento cada uno de tales estamentos gozaba de un poder decisorio idéntico, lo cual, por descontado, era una manera obvia de conceder un impacto mucho mayor al sufragio de las dos primeras clases, mucho menos numerosas que la tercera. La estrategia se ha seguido usando hasta nuestros días sin interrupción, siglo tras siglo. Así, la gran reforma electoral británica del siglo XIX se centró sobre todo en acabar con los «burgos podridos», distritos rurales brutalmente sobrerrepresentados ${ }^{14}$. Durante la primera mitad del siglo XX, Kelsen denunciaba en sus escritos tempranos la «geometría electoral» del sistema representativo del viejo Imperio Austro-húngaro, basada en la división de la población en distritos extraordinariamente diferentes de acuerdo al valor de voto de sus habitantes ${ }^{15}$. El hecho de que en el siglo XXI este tipo de desigualdad electoral siga existiendo en numerosos ordenamientos (entre ellos el nuestro, como veremos) demuestra hasta qué punto la estrategia realmente eficaz para otorgar más votos a ciertos electores nunca ha sido la explícita (otorgar más votos a unos que a otros) sino la velada (otorgar a todos un voto, pero de diferente valor).

La ciencia política denomina a esta desigualdad «malapportionment», un vocablo que a su vez viene de «apportionment». Así, «apportionment» sería el reparto de los escaños entre las circunscripciones, de tal modo que «malapportionment» podría traducirse por algo así como «reparto incorrecto». Entre nosotros se han propuesto, respectivamente, los términos «prorrateo» y «prorrateo desviado».

14 Ertman T., «The Great Reform Act of 1832 and british democratization», Comparative Political Studies, 43, 2010.

15 LaGi S., El pensamiento político de Hans Kelsen (1911-1920): Los orígenes de «Esencia y valor de la democracia», Biblioteca Nueva, Madrid, 2007, 141-147. 
Aquí utilizaremos sencillamente «voto desigual». Por un lado, no hay peligro de que se confunda con la primera manera de desigualar el voto, ya erradicada; por otro, y sobre todo, el término «voto desigual» encaja mejor con la perspectiva que seguiremos en el presente texto, que será más jurídica que politológica, centrándose más en los derechos subjetivos de los ciudadanos que en las propiedades sistémicas del proceso electoral.

En la Tabla 1 se refleja la desigualdad del voto de los españoles establecida para las elecciones al Congreso de los Diputados de abril del año 2019. Se trata de valores muy obvios, calculados muchas veces desde $1977^{16}$, si bien las dos últimas columnas que ofrecemos aquí necesitarán alguna aclaración.

Tabla 1. Voto desigual en España (elecciones de 2019)

\begin{tabular}{|l|c|c|c|c|c|}
\hline Circunscripción & Escaños & Población & $\begin{array}{c}\text { Habitantes } \\
\text { por escaño }\end{array}$ & $\begin{array}{c}\text { Voz de } \\
\text { cada voto }\end{array}$ & $\begin{array}{c}\text { Votos por } \\
\text { elector }\end{array}$ \\
\hline Madrid & 37 & 6.578 .079 & 177786 & 5,62 & 1 \\
\hline Barcelona & 32 & 5.609 .350 & 175292 & 5,70 & 1,01 \\
\hline Valencia & 15 & 2.547 .986 & 169866 & 5,89 & 1,05 \\
\hline Sevilla & 12 & 1.939 .887 & 161657 & 6,19 & 1,10 \\
\hline Alicante & 12 & 1.838 .819 & 153235 & 6,53 & 1,16 \\
\hline Málaga & 11 & 1.641 .121 & 149193 & 6,70 & 1,19 \\
\hline Murcia & 10 & 1.478 .509 & 147851 & 6,76 & 1,20 \\
\hline Asturias & 7 & 1.028 .244 & 146892 & 6,81 & 1,21 \\
\hline S. C. de Tenerife & 7 & 1.018 .510 & 145501 & 6,87 & 1,22 \\
\hline Bizkaia & 8 & 1.149 .628 & 143704 & 6,96 & 1,24 \\
\hline Balears, Illes & 8 & 1.128 .908 & 141114 & 7,09 & 1,26 \\
\hline Coruña, A & 8 & 1.119 .351 & 139919 & 7,15 & 1,27 \\
\hline Palmas, Las & 8 & 1.109 .175 & 138647 & 7,21 & 1,28 \\
\hline Cádiz & 9 & 1.238 .714 & 137635 & 7,27 & 1,29 \\
\hline Zaragoza & 7 & 954.811 & 136402 & 7,33 & 1,30 \\
\hline Pontevedra & 7 & 941.772 & 134539 & 7,43 & 1,32 \\
\hline Tarragona & 6 & 795.902 & 132650 & 7,54 & 1,34 \\
\hline Córdoba & 6 & 785.240 & 130873 & 7,64 & 1,36 \\
\hline & & & & & \\
\hline
\end{tabular}

16 Tablas similares se encontrarán en VIDAL PRADO C., El sistema electoral español: una propuesta de reforma, Universidad de Navarra, 1993 (elecciones de 1977 a 1989); GARROTE DE MARCos M., El ámbito territorial de las elecciones al Congreso de los Diputados en España, Congreso de los Diputados, Madrid, 2008 (de 1977 a 2004); URdÁNOZ GANUZa J., «Legislación electoral y posibilidades participativas», Oñati Socio-legal Series, $v 7, n$, 2017 (elecciones de 2008) y URdÁNOZ GanuZa J. y del Olmo, E., Reformar el sistema electoral, Gedisa, Barcelona, 2019 (elecciones de 2016). Los valores son básicamente iguales desde 1977 y, aunque puede haber pequeñas variaciones, carecen de relevancia conceptual para el tipo de argumentación que se despliega en el artículo. 


\begin{tabular}{|c|c|c|c|c|c|}
\hline Circunscripción & Escaños & Población & $\begin{array}{l}\text { Habitantes } \\
\text { por escaño }\end{array}$ & $\begin{array}{c}\text { Voz de } \\
\text { cada voto }\end{array}$ & $\begin{array}{c}\text { Votos por } \\
\text { elector }\end{array}$ \\
\hline Granada & 7 & 912.075 & 130296 & 7,67 & 1,36 \\
\hline Navarra & 5 & 647.554 & 129511 & 7,72 & 1,37 \\
\hline Jaén & 5 & 638.099 & 127620 & 7,84 & 1,39 \\
\hline Girona & 6 & 761.947 & 126991 & 7,87 & 1,40 \\
\hline Gipuzkoa & 6 & 720.592 & 120099 & 8,33 & 1,48 \\
\hline Almería & 6 & 709.340 & 118223 & 8,46 & 1,50 \\
\hline Cantabria & 5 & 580.229 & 116046 & 8,62 & 1,53 \\
\hline León & 4 & 463.746 & 115937 & 8,63 & 1,53 \\
\hline Castellón & 5 & 576.898 & 115380 & 8,67 & 1,54 \\
\hline Toledo & 6 & 687.391 & 114565 & 8,73 & 1,55 \\
\hline Badajoz & 6 & 676.376 & 112729 & 8,87 & 1,58 \\
\hline Lleida & 4 & 432.866 & 108217 & 9,24 & 1,64 \\
\hline Huelva & 5 & 519.932 & 103986 & 9,62 & 1,71 \\
\hline Valladolid & 5 & 519.851 & 103970 & 9,62 & 1,71 \\
\hline Ciudad Real & 5 & 499.100 & 99820 & 10,02 & 1,78 \\
\hline Cáceres & 4 & 396.487 & 99122 & 10,09 & 1,79 \\
\hline Albacete & 4 & 388.786 & 97197 & 10,29 & 1,83 \\
\hline Burgos & 4 & 357.070 & 89268 & 11,20 & 1,99 \\
\hline Melilla & 1 & 86.384 & 86384 & 11,58 & 2,06 \\
\hline Ceuta & 1 & 85.144 & 85144 & 11,74 & 2,09 \\
\hline Guadalajara & 3 & 254.308 & 84769 & 11,80 & 2,10 \\
\hline Salamanca & 4 & 331.473 & 82868 & 12,07 & 2,15 \\
\hline Lugo & 4 & 331.327 & 82832 & 12,07 & 2,15 \\
\hline Álava & 4 & 328.868 & 82217 & 12,16 & 2,16 \\
\hline Rioja, La & 4 & 315.675 & 78919 & 12,67 & 2,25 \\
\hline Ourense & 4 & 309.293 & 77323 & 12,93 & 2,30 \\
\hline Huesca & 3 & 219.345 & 73115 & 13,68 & 2,43 \\
\hline Cuenca & 3 & 197.222 & 65741 & 15,21 & 2,70 \\
\hline Zamora & 3 & 174.549 & 58183 & 17,19 & 3,06 \\
\hline Palencia & 3 & 162.035 & 54012 & 18,51 & 3,29 \\
\hline Ávila & 3 & 158.498 & 52833 & 18,93 & 3,37 \\
\hline Segovia & 3 & 153.342 & 51114 & 19,56 & 3,48 \\
\hline Teruel & 3 & 134.572 & 44857 & 22,29 & 3,96 \\
\hline \multirow[t]{2}{*}{ Soria } & 2 & 88.600 & 44300 & 22,57 & 4,01 \\
\hline & & 46.722 .980 & & & \\
\hline
\end{tabular}

Fuente: columnas 1 y 2: Real Decreto 129/2019 (elecciones de 28 de abril). Columna 3: Población de Derecho a 1 de enero de 2019, Ine.es. Columnas 4, 5 y 6: elaboración propia. 
Las tres primeras columnas son datos desnudos. La cuarta es muy intuitiva: se trata del número de habitantes «representados» por cada escaño, un número diferente según los diferentes grupos de electores en los que nos divide el sistema electoral. La quinta es en el fondo la misma variable que la anterior, pero invertida (la imagen en el espejo, si se quiere). Se obtiene dividiendo los escaños entre los habitantes, de tal modo que lo que obtenemos es algo así como las «partículas de escaño» que la convocatoria electoral del BOE otorgó en 2019 a cada elector del sistema electoral español. Estas «partículas de escaño» se ofrecen multiplicadas por 1 millón, por lo que en realidad son «millónesimas de escaño». Se hace así tan solo para eliminar decimales y tornar la unidad de medida algo más humana: es más cómodo hablar de 5.86 que de 0.00000586 . Sobra decir que tal multiplicación, al ser uniforme, carece de incidencia alguna. A esta variable la denominamos, como se habrá visto, «voz de cada voto». La razón es que el término «voto» deriva etimológicamente de «voz». Nicolás de Cusa utilizaba la expresión «vocum pluralitatem»; los Niveladores ingleses — pioneros como Lilburne, Walwyn y Overton, que merecerían un lugar en la historia de la democracia mayor que el que les venimos dando — hablaban de «the major voyces»; Hobbes se refirió a «the voice of the greater number $»^{17}$. Con el tiempo, la palabra «voz» se transformaría en el término «voto». Un voto es, en efecto, la voz que se nos permite expresar en una determinada decisión colectiva. Si un voto tiene más valor que otro, la expresión intuitiva para describir tal estado de cosas consiste afirmar que unos tienen más voz que otros. Una voz que no se mide en decibelios, volumen o potencia acústica, sino en representación política en el parlamento (incluso físicamente, puesto que esa fuerza de los votos se remite a la mayor cantidad de «partículas de escaño» que contiene cada uno de ellos, algo empíricamente irrefutable).

\section{El voto como metáfora democrática}

La sexta columna de la Tabla 1 expresa una variable que compara la fuerza de unos votos con otros en el interior del sistema. La dinámica que sigue su cálculo es muy sencilla: se establece que los votantes con menos voz de todos (los madrileños, en este caso) tienen un voto, y — por comparación con ellos, mediante una sencilla regla de tres - se calcula cuantos votos como los madrileños tienen los demás electores. Así, el hecho de que la variable arroje un valor de 3.06 para los zamoranos nos indica que mientras que el sistema les concede a los madrileños un voto, a los zamoranos les concede tres votos (ignoraremos a los efectos de la argumentación el resto de 0.06).

17 Nicolás de Cusa, De concordantia catholica, (1433), Editado por Gerhardus Kallen, F. Meiner, 1939, p. 77; Lilburne, J. et. al., Three Agreements of the People, (1647-49), Indianapolis, Liberty Fund, 2016, p. 13; HOBBES, T., Leviathan, or the matter, form and power of a commonwealth, (1651), en: The english works of Thomas Hobbes of Malmesbury, William Molesworth, vol. III, John Bohn, 1839, p. 151. 
Esta última variable nos permite una pequeña digresión. Si estamos diciendo que el voto de un zamorano cuenta como tres votos... ¿entonces los zamoranos tienen un voto o tienen tres? Estrictamente hablando, tienen un voto. Un voto que «pesa» o «vale» tres veces más. De hecho, tenemos incluso la variable empírica que atrapa esa fuerza o voz de los votos — las partículas de escaño- y podemos medirla con absoluta precisión empírica, de la misma manera que podemos medir los decibelios del sonido o las fotones de la luz: el voto de un madrileño tiene 5.62 partículas, mientras que el de un zamorano tiene 17.19, esto es, tres veces más. Un solo voto, diferente valor. De acuerdo, pero, de nuevo, ¿por qué, entonces, la construcción lingüística «tienen tres votos» encaja como un guante, por así decir, en nuestro marco perceptivo? ¿Por qué nos parece evidente que es como si tuvieran tres «votos»? ${ }^{18}$

La respuesta consiste en que esos votos de la última columna lo son solo metafóricamente, pero que a su vez esa metáfora goza de una fuerza intuitiva avasalladora. Son votos solo metafóricamente porque son una comparación del impacto de unos ciudadanos con respecto a otros, y sólo en ese marco puramente relativo adquieren sentido como expresión lingüística. Que una persona tenga un voto y otra tenga tres tan solo nos ofrece el dato desnudo del mayor poder que a una se le confiere frente a la otra, no nos dice nada más (ni nada menos, claro). Pero resulta muy sintomático que esa manera de expresarnos funcione en este contexto. En otros ámbitos no lo hace. Cuando comparamos la riqueza, por ejemplo, no utilizamos algo así como un lote estándar que designa una cantidad dada de renta de un individuo, de tal modo que, por comparación al mismo, podemos calibrar la riqueza de todo el mundo. No decimos «fulano tiene siete fortunas, mientras yo tengo la mitad de una fortuna». No existe el término «fortuna» en ese sentido, existen los euros. Cuando nos referimos a la altura de las personas, usamos los centímetros. No hacemos comparaciones con respecto al más bajo del grupo, no decimos «mido 1.7 alturas». No utilizamos las expresiones «altura»o «fortuna» así... ¿Por qué entonces en el contexto electoral sí que entendemos el significado de la expresión «los zamoranos tienen tres votos»? ¿Cuál es la fuerza de ese uso metafórico de la expresión «voto»? Las razones parecen ser sobre todo dos.

La primera es moral y hunde sus raíces en la intuición democrática de la igualdad. Dworkin lo expresa diciendo que el reconocimiento de alguien «como un miembro moral» de la comunidad implica asumir que ese alguien posee «un estatus igual» en su interior ${ }^{19}$. La intuición democrática considera a los demás conciudadanos dignos de igual valor y les concede de inmediato igual consideración. Esa

18 La expresión es de Duverger: «supongamos dos circunscripciones que eligen cada una a un diputado; la primera, poblada por 50.000 electores; la segunda, por 100.000. Oficialmente, cada elector no tiene más que un voto. Pero, de hecho, todo sucede como si los electores de la primera circunscripción tuvieran dos votos cada uno, y los electores de la segunda sólo uno». En Duverger M., Instituciones políticas y derecho constitucional, Ariel, Barcelona, 1980, p. 99, cursiva nuestra.

19 Dworkin R., Freedom's law: the moral reading of the American Constitution, Oxford University Press, 1999 , p. 24.

UNED. Teoría y Realidad Constitucional, núm. 45, 2020, ISSN 1139-5583, pp. 353-378 
igual «consideración», ese igual «valor» o esa igual «dignidad» —expresiones todas que son proyección de un mismo ideal - se reflejan en la capacidad de votar y en la inmediata exigencia de que cada voto valga lo mismo. El voto no es solo parte de un proceso de decisión colectiva, es también un acto de reconocimiento de los demás en aquello que tienen de único: su individualidad, su personalidad, el hecho de ser un «otro-yo». Por eso nada tiene de extraño que - frente a lo que hacemos con el dinero, la altura o la velocidad - valoremos o midamos o calibremos la participación de los otros en «lotes» unívocos, uniformes e idénticos entre sí, porque así es como el ideal democrático concibe a los miembros de la sociedad, como miembros absolutamente iguales de la comunidad. Decir unos tienen 5.62 miliescaños y otros 17.19 es una descripción precisa de un cierto estado de cosas. Afirmar que unos tienen tres veces más votos que otros es algo más: en su mera formulación, esa oración no solo describe algo desde un punto de vista empírico, además lo denuncia desde uno democrático. Por eso funciona.

La segunda razón por la que hablar el lenguaje de los votos en este sentido resulta tan intuitivo es cuantitativa. Desde el punto de vista del impacto en la decisión final, conceder a un grupo de votantes tres votos o concederles un único voto que vale tres veces más viene a ser lo mismo, una manera evidente de beneficiar a ese grupo sobre los demás. En qué medida el beneficio en uno u otro caso sea exactamente el mismo no es algo, sin embargo, que pueda establecerse a priori, pues dependerá de múltiples circunstancias (el sistema electoral de cada grupo de votantes, la participación, el número de escaños que elijan, etc). Pero no hay duda de que los 13.887 ciudadanos españoles (agrupados electoralmente en Soria) que votaron en abril de 2019 por un determinado partido y a los que el sistema otorgó un diputado tenían un voto que valía más, mucho más, que el de los 84.945 que (agrupados en Barcelona) votaron por otro partido y a los que el sistema, sin embargo, no concedió ninguna representación en el Congreso ${ }^{20}$. Otorgar a unos más poder de voto en su único voto es, a efectos prácticos, idéntico a concederles más votos, por eso también desde este punto de vista meramente cuantitativo tiene todo el sentido del mundo hablar en esos términos, pues es evidente que todo ha ocurrido como si a los sorianos les hubieran dado muchos más votos que a los barceloneses.

\section{IGUALDAD, PROPORCIONALIDAD Y LA EQUIVOCIDAD ALEMANA}

Nuestro Tribunal Constitucional no tuvo ocasión de abordar la cuestión del sufragio igual hasta el año $2011^{21}$. Sin embargo, sí se había referido a la «igual-

20 Datos oficiales de las elecciones generales de abril de 2019, disponibles en http://www.infoelectoral. mir.es/infoelectoral $/ \mathrm{min} /$.

21 En la STC 19/2011, relativa al sistema electoral autonómico de Castilla-La Mancha, sobre la que volveremos.

UNED. Teoría y Realidad Constitucional, núm. 45, 2020, ISSN 1139-5583, pp. 353-378 
dad» electoral en sentencias en las que lo recurrido eran cuestiones relativas más bien a la proporcionalidad del sistema electoral ${ }^{22}$. De hecho, puede afirmarse que existe - tanto desde la Ciencia Política como desde el Derecho Constitucionalcierta confusión entre ambas categorías. Se empieza hablando de proporcionalidad y se termina hablando, sin una justificación detallada del salto categorial al que se somete a la argumentación, de igualdad ${ }^{23}$. Conviene por eso deslindar ambas cosas.

La igualdad (del sufragio) y la proporcionalidad (de los resultados) se distinguen en varios aspectos. 1) Titularidad: la igualdad puede predicarse de todos los electores con derecho a voto; la proporcionalidad solo puede aplicarse a los votos emitidos y válidos ${ }^{24}$. 2) Tiempo: la igualdad existe (o no) antes de la votación; la proporcionalidad solo aparece tras el resultado arrojado por las urnas. 3) Posibilidad: la igualdad total es perfectamente factible; la proporcionalidad absoluta es imposible ${ }^{25}$.4) Naturaleza: la igualdad es un trasunto puramente jurídico, deci-

22 Hasta 2005, tales sentencias están recogidas en DuQue Villanueva J.C., Elecciones políticas y Tribunal Constitucional. Jurisprudencia constitucional en materia electoral, 1980-2005, Thomson Aranzadi, Pamplona, 2006. Tras esa fecha, la sentencia más relevante es la mencionada 19/2011.

23 Con respecto a la Ciencia Política, se ha afirmado que «la ciencia política comparada parece haber llegado a un cierto consenso con respecto a (que...) parece aceptada la equiparación entre proporcionalidad e igualdad (y, si se quiere, justicia) en el sistema electoral. En este sentido, los sistemas proporcionales son las formulas institucionales que mejor encarnarían la consecución de ese objetivo de igualdad en el ejercicio del voto. Sin embargo, esta última afirmación no iría en detrimento (...) de la posibilidad de que el sistema mayoritario cumpliese hasta cierto punto con el principio de igualdad de voto». En MonTero J.R. y Riera P., «El sistema electoral español: cuestiones de desproporcionalidad y de reforma», Anuario de la Facultad de Derecho de la Universidad Autónoma de Madrid, 13, 2009, p. 230. Con respecto al Derecho Constitucional, valga la siguiente cita: «En general, las fórmulas electorales proporcionales pretenden establecer una relación simétrica (proporcional) entre votos y escaños, es decir, entre voluntad popular y representación, a diferencia de las mayoritarias, cuya principal finalidad es decidir una mayoría de gobierno. El objeto de aquella simetría o proporcionalidad es reflejar en la representación la composición plural de la sociedad, y favorecer el consenso, especialmente en sociedades poco homogéneas, por lo que no perjudica, más bien refuerza, el principio de igualdad en el sufragio, ya que cada ciudadano, y cada candidato o formación, consiguen una cuota de representación en relación directa con el número de sufragios manifestados u obtenidos», en LÁzARo Riol A., «Proporcionalidad, territorialidad e igualdad en los sistemas electorales autonómicos», Revista Española de Derecho Constitucional, 2000, p. 226.

24 Esta diferencia es cristalina en ejemplo de Valladolid del epígrafe II : la igualdad en el sufragio afecta a los 418.927 electores vallisoletanos, puesto que todos, en cuanto que ciudadanos, tienen otorgado un voto (capacidad) que será, o no, igual. La mayor o menor proporcionalidad, sin embargo, solo puede predicarse con respecto a los 332.264 votantes que emitieron un voto (decisión) válido a ciertos partidos políticos. Es interesante considerar — si bien tal cosa escapa a la línea argumental del presente artículo - si el voto en blanco habría o no de computar a estos efectos como voto «válido» (ahora no lo hace). Pueden verse dos propuestas divergentes en URdánoz GanuZa J., «Un nuevo sistema electoral», Revista De Estudios Politicos, 2004 y en Mora Molina J.J.,»El sistema electoral español, una propuesta realista», Anales de la Cátedra Francisco Suárez, 46, 2012.

25 Hay muchísimos sistemas electorales igualitarios: Holanda, Alemania, Estados Unidos, la mayor parte de los sistemas electorales autonómicos españoles, todos los miles de sistemas electorales municipales de España, etc. La proporcionalidad total, por el contrario, es imposible. Un sistema que asegurara a todos los electores una representación absolutamente proporcional sería, como decía Kelsen, algo parecido a la democracia directa: uno se votaría a sí mismo y saldría elegido. 
dido en el BOE; la proporcionalidad es tanto una cuestión jurídica (influye el sistema electoral establecido) como elegida (depende también de cómo hayan votado los electores).

A pesar de todos estos rasgos distintivos, la línea que separa la igualdad de la proporcionalidad en ocasiones se difumina. El origen de la confusión probablemente se halle en una sentencia de 1952 del Tribunal Constitucional Federal de Alemania, en la que distinguió entre: 1) la igualdad en el «valor numérico» del voto, que ha de ser respetada por todo sistema electoral, sea proporcional o mayoritario (nuestra «igualdad»); y 2) la igualdad del «valor de logro», exigible solo a los sistemas proporcionales (nuestra «proporcionalidad»). El Tribunal se refería a algo muy obvio: si pensamos en cualquier resultado proporcional completamente proporcional, como suele decirse - es inmediato que cada votante ha recibido (o logrado) lo mismo. Supongamos que se eligen 100 escaños. En ese caso, cada uno de los votantes de un partido con un $4 \%$ del voto (que se llevará 4 escaños) reciben lo mismo que cada uno de los de otro partido con un $78 \%$ del voto (que se llevará 78 escaños). En ese sentido, el «valor de logro» de cada voto es idéntico. Con un sistema mayoritario no ocurre igual, unos se llevan todo y otros nada.

Planteada así la cuestión, la proporcionalidad puede describirse en términos de igualdad: todos los votos deben pesar igual, valer igual, etc. Eso ha permitido un escenario terminológico un tanto confuso, que podemos reflejar a partir de la siguiente enumeración de nombres asignados a ambas categorías:

a) Categoría «IGUALDAD (del sufragio)»: Igualdad en el valor de voto, Igualdad en el peso del voto, igualdad numérica, igualdad formal, igualdad aritmética.

b) Categoría «PROPORCIONALIDAD (de los resultados)»: Igualdad en el valor de voto, Igualdad en el peso del voto, igualdad de logro, igualdad material.

Lo problemático aquí es que cualquier autor (o Tribunal) puede escoger un término de cada categoría para distinguir ambas propiedades. El amable lector puede hacer la prueba, escogiendo al azar una denominación de las asignadas a cada categoría. Verá que la pareja de términos que haya elegido, sea la que sea, se sostiene (siempre, claro, que no se escoja el mismo vocablo). Sobra decir que cada autor (o Tribunal) mantiene la coherencia con la concreta decisión que haya adoptado en su caso, pero el resultado final de conjunto es, cuanto menos, equívoco.

A esta enrevesada mixtura terminológica se ha de añadir, además y sobre todo, que las justificaciones normativas deslizadas para ambas propiedades son idénticas. En su sentencia de 1952 el Tribunal alemán define la «igualdad de logro» (la proporcionalidad) como el hecho de que todos los votos deben tener «el mismo poder», es decir, que todos los votantes deben tener «igual influencia 
sobre el resultado electoral» ${ }^{26}$. Son, como se ve, justificaciones exactas a las esgrimidas para fundamentar la igualdad (del sufragio), y ello por una razón evidente: ambas propiedades se basan en la idea del trato igual. Pero hay un criterio claro y distinto para diferenciar una de otra. No debemos tanto atender al qué (que es en buena medida idéntico, e induce a confusión) como dejar claro o bien el quién (titularidad: ¿hablamos de todos los electores o solo de los votantes?) o bien el cuándo (tiempo: ¿nos situamos antes o después de las urnas?). Cualquiera de esos dos elementos resulta suficiente para aclarar la cuestión sin atisbo de duda ${ }^{27}$.

En nuestro país, prácticamente todas las reclamaciones elevadas hasta la fecha ante el Tribunal Constitucional han versado sobre proporcionalidad, si bien tanto los demandantes como el tribunal las han abordado en términos de igual$d a d^{28}$. Con respecto a los primeros, son siempre partidos políticos (o sus candidatos), y lo que aducen son cuestiones posteriores a las urnas. Por razones evidentes, formulan sus demandas en términos de «igualdad», ya que si un partido con 300.000 votos recibe cinco escaños y otro con los mismos votos no recibe ninguno, es casi inevitable que, desde un punto de vista normativo, la idea de igualdad de trato pase a primer plano ${ }^{29}$. Con respecto al Tribunal, desde su sentencia $75 / 1985$ ha enfocado las cuestiones de proporcionalidad en buena medida como cuestiones relacionadas con la igualdad de acceso a los cargos públicos recogida en el artículo 23.2.

Pero se trata siempre de proporcionalidad de los resultados, no de igualdad de sufragio. $\mathrm{O}$, si queremos, se trata del tipo concreto de igualdad de trato entre los votantes de dos o más partidos — no entre todos los electores del sistema - que deberíamos denominar «proporcionalidad». La igualdad en el sufragio es otra cosa, y está antes del trato otorgado a los partidos. Una demanda de amparo por vulneración de la igualdad de sufragio no debería plantearse por parte de un partido o candidato, sino por parte de un ciudadano, quien — contra viento y marea, al parecer — sigue siendo, en buena lógica democrática, el verdadero dueño y

26 Las citas literales lo son de la sentencia BVerfGE 1, 208, tal y como se ofrecen traducidas al castellano en Nohlen D. y Nohlen N., «El sistema electoral alemán y el tribunal constitucional federal (la igualdad electoral en debate. Con una mirada a Venezuela)», Elecciones, 2007 , p. 145.

27 El Tribunal Constitucional austriaco ha diferenciado especialmente bien ambas propiedades: Nohlen D. y Nohlen N., op. cit., pp. 237-238. Y, entre nosotros, también lo ha hecho el Informe del Consejo de Estado: op. cit., pp. 177-178. La dinámica más extendida, sin embargo, consiste en diferenciar correctamente ambas tendencias en la pura teoría, para, después, a la hora de enfrentarse a casos concretos, saltar de una categoría a otra de un modo un tanto equívoco. En su sentencia 19/2011, nuestro Tribunal se remite a la distinción alemana, utilizando en su FJ9 los términos «igual valor numérico» e «igual valor de resultado», pero, más allá de eso, resulta indiscutible que, en nuestro ordenamiento electoral para el Congreso, ambos (también el primero) no se encuentran garantizados sino todo lo contrario.

28 La única excepción es la demanda que condujo a la señalada STC 19/2011. La habitual y confusa mixtura entre igualdad y proporcionalidad la describe muy bien, por lo demás, el Consejo de Estado: «en España, al igual que en otros ordenamientos, el principio de igualdad se ha invocado como límite a las desviaciones legislativas del principio de la proporcionalidad electoral consagrado en el artículo 68.3 de la Constitución». Informe del Consejo de Estado, op. cit., p. 179, cursiva nuestra.

29 V. Garrote de Marcos M., op. cit., p. 335. 
señor del sufragio activo, un derecho que jamás puede pertenecer a los partidos. Y ese ciudadano o ciudadana no tendría necesidad alguna de esperar al resultado, pues es la mera convocatoria electoral la que torna su sufragio desigual con respecto al de sus conciudadanos - desigual en la mera capacidad de influir en el resultado - con absoluta independencia de lo que ocurra tras las urnas.

\section{EL SUFRAGIO IGUAL EN EL CONSTITUCIONALISMO COMPARADO}

El derecho al sufragio igual aparece explícitamente recogido en las principales declaraciones internacionales de derechos y en la mayoría de las constituciones democráticas del mundo. Con respecto a las primeras, la Declaración Universal de Derechos Humanos de 1948 lo recoge en su artículo 21.3 y el Pacto Internacional de Derechos Civiles y Políticos de 1966 en su artículo 25.2. Con respecto a las segundas, la mayor parte los estados miembros de la Unión Europea incluyen el sufragio igual en sus textos constitucionales ${ }^{30}$. ¿A qué puede referirse la expresión «sufragio igual» recogida en tales textos legales?

De los dos tertia propios del voto-capacidad que hemos examinado, el primero se encuentra, que sepamos, erradicado. Existe en la pura teoría, pero no en la realidad empírica, ya que sería sencillamente intolerable que en el siglo XXI un ordenamiento democrático concediera más votos a unos que a otros. Del otro tipo de desigualdad, por el contrario, cabe afirmar, por un lado, que se encuentra muy extendida y, por otro, que buena parte de los tribunales constitucionales de las democracias consolidadas se han ocupado de proteger a sus ciudadanos frente a ella. Con respecto a lo primero, no es este el lugar para descender a un examen internacional al respecto, pero sí procede reflejar la situación de nuestro país. En un estudio pionero de 2001, España alcanzaba el puesto 62 (de 78 democracias examinadas) en lo relativo a la desigualdad en el valor del voto de sus ciudadanos. El número 78 (el país con el sufragio más desigual del mundo) era Tanzania ${ }^{31}$. En un estudio más amplio y reciente, del año 2017, seguíamos igual: de 160 países (es decir, incluyendo dictaduras y regímenes de todo pelaje), estamos en el puesto 108 en lo relativo a voto desigual (siendo el último, con el puesto 160, Haití).

30 Una enumeración de los artículos concretos referidos al sufragio igual incluidos en diversas constituciones europeas se hallará en el Informe del Consejo de Estado, op. cit., p. 162. Con respecto al más genérico principio de igualdad, las únicas que no lo recogen en sus constituciones (lo que no quiere decir que no lo garanticen, en su caso, por otros medios) son Gran Bretaña, Noruega y Suecia. V. MCCrudden C. y PrechaL S., «The Concepts of Equality and Non-discrimination in Europe: A practical approach», European Commission, Directorate-General for Employment, Social Affairs and Equal Opportunities, Unit G, 2, 2009, p. 3.

31 SAmuels D. y SNYDER R., "The value of a vote: Malapportionment in comparative perspective», British Journal of Political Science, 31, 2001. También Simón CosAnO P., «La desigualdad y el valor de un voto: el «malapportionment» de las Cámaras Bajas en perspectiva comparada», Revista De Estudios Politicos, 2009 . 
Cuando nos comparamos tan solo con los regímenes democráticos, estamos en el puesto 76 de $96^{32}$. De los 28 países de la UE, somos siempre el último, con la excepción de Luxemburgo y Chipre, que, por muchos motivos, no resultan comparables a nuestro país ${ }^{33}$.

Con respecto a lo segundo, es notable la actividad al respecto por parte de los tribunales constitucionales de buena parte de las democracias de nuestro entorno. Quizás la mejor manera de introducir la cuestión sea repetir lo dicho un poco más arriba: «sería sencillamente intolerable que en el siglo XXI un ordenamiento democrático concediera más votos a unos que a otros». Si eso es cierto para la desigualdad en el número de votos, lo es igualmente — pues, como ya hemos visto, el sustrato normativo es idéntico- para la igualdad en el valor del voto. Desde cualquier comprensión de lo que significa la voz «democracia», no hay ninguna diferencia moral reseñable en tratar a alguien peor concediéndole menos votos que en hacerlo devaluando su voto. Es exactamente lo mismo: denegar su reconocimiento moral como ciudadano igual. Así lo han visto tanto varios altos tribunales que han tenido oportunidad de pronunciarse al respecto como otras instancias jurídicas nacionales e internacionales.

Muy sucintamente, exponemos aquí algunas de las directrices establecidas con respecto al sufragio desigual. En Estados Unidos el Tribunal Supremo estableció en 1962 que no era aceptable ningún grado de desigualdad (0\%), y que la misma había de ser evitada «as nearly as is practicable» ${ }^{34}$. En Alemania, en 1963, se estableció también un $0 \%$ de desigualdad máxima (junto a una horquilla de entre el 15 y el $25 \%$ en casos extraordinarios, pero solo para los distritos uninominales $\left.{ }^{35}\right)$. En

32 ONG K.-M., KASUYA Y. y MORI K., «Malapportionment and democracy: a curvilinear relationship», Electoral Studies, 49, 2017.

33 El Gran Ducado de Luxemburgo carece de una segunda cámara y, sin duda por ello, no incluye el voto igual en su Constitución. Sí garantiza, en su artículo 51, el sufragio universal y directo. Algo muy parecido, aunque agravado, ocurre en Chipre, cuya constitución no reconoce el voto igual —sí el universal, directo y secreto, en su artículo 93 - y articula un complejo sistema representativo en el que el parlamento se reparte entre las comunidades griega ( $70 \%$ de los escaños) y turca (30\%).

34 Tras la sentencia Baker vs. Carr, 369 U.S 186 (1962) los distritos habrán de conseguir la igualdad de voto siempre que sea posible. El Tribunal Supremo ha llegado a tumbar desigualdades de un $0.7 \%$. V. SÁNCHEZ MuÑoz Ó., op. cit., pp. 507 y 512; Informe del Consejo Estado, op. cit. p. 166.

35 Ibid. p. 508 e Informe del Consejo de Estado, op. cit., p. 169. Los dos porcentajes del 15 y el $25 \%$ han de entenderse en su contexto. El sistema electoral alemán es complejo, y ha sido, y continúa siendo, muy mal entendido en ocasiones. En lo que nos atañe aquí, ambos porcentajes se refieren sólo a la delimitación de los distritos uninominales en los que se emiten los «segundos votos». Tales distritos juegan un papel subordinado en la configuración del parlamento, que depende por completo de la distribución de poder entre los partidos decidida por los «primeros votos», los realmente decisivos. Para esos primeros votos la igualdad de sufragio está garantizada (ahí los porcentajes del 15 o el 25\% ni se plantean: el sufragio es igual). La influencia de los segundos votos es de orden más bien «intra-partidista»: afecta a la cuestión de quiénes, dentro de un partido, consiguen los escaños que ese partido obtenga con los primeros votos. De hecho, el Tribunal Constitucional Federal forzó al Bundestag a modificar la Ley Electoral Federal en 2013 precisamente para impedir que la influencia de tales distritos afectara a la igualdad de voto. Esa influencia, por lo demás, aunque menor hasta esa fecha (e inexistente después), rozaba en ocasiones lo estrafalario: en 2005, tras el fallecimiento de un candidato pocos días antes de las elecciones y la repetición de las elecciones en su distrito uninominal, resultó 
Canadá, en 1964, un 25\% máximo (y un 35\% para «circunstancias extraordinarias» $)^{36}$. En Francia, en 1985, un $20 \%$ para «casos excepcionales debidamente justificados» ${ }^{37}$. En Italia, en 1993 , un $10 \%$ (y un $15 \%$ en casos con minorías étnicas o culturales) $^{38}$. Los porcentajes máximos se calculan en todos los casos como porcentajes de desviación con respecto a la media del país.

No podemos descender aquí a un análisis detallado de las diversas decisiones, debidas en muchos casos a la intervención de Tribunales Constitucionales, tomadas internacionalmente ${ }^{39}$. No parece discutible, con todo, que España configura una señalada excepción a una tendencia generalizada. Una tendencia que cristaliza en lo que la Comisión de Venecia denomina el «patrimonio electoral europeo», cuyo «núcleo esencial» son «los principios constitucionales del derecho electoral como el sufragio universal, igual, libre, secreto y directo» ${ }^{40}$. Para el principio del sufragio igual, la desviación máxima permitida habrá de ser, de acuerdo a la Comisión, de un $10 \%$, ampliable al $15 \%$, un porcentaje que nunca ha de sobrepasarse excepto en determinadas «circunstancias realmente especiales» ${ }^{41}$. En España, si a partir de los datos de la Tabla 1 calculamos las desviaciones con respecto a un hipotético $100 \%$, nos encontramos con que los dos extremos son: $75 \%$ (Madrid) y $301 \%$ (Soria). Entre ellos se alinean otros 50 valores, en una

que el hecho de que no votar por un determinado partido era mejor para ese partido, y por tanto tal partido hizo campaña solicitando a sus simpatizantes que no le votaran. Un muy buen resumen de los motivos que llevaron al Tribunal a involucrarse se encontrará en VÁZquez LAPUENTE M. y Jiménez SERAL P., «El nuevo modelo de reparto de escaños en el sistema electoral alemán», Cuadernos Manuel Giménez Abad, 7, 2014. Con anterioridad a esa decisión, el Tribunal Constitucional Federal tuvo que intervenir repetidas veces para salvaguardar la igualdad de sufragio frente a los avatares que la propia complejidad del sistema provocaba en el mismo. V. Nohlen D. y NoHLen N., op. cit., y Prado C.V. El sistema electoral alemán y su posible implantación en España, Tirant lo Blanch, 2012, cap. IV.

36 Ibid., p. 513.

37 La decisión inicial, la CC 85-196 DC, de 8 de Agosto de 1985, se originó a raíz de la denuncia ante el Consejo Constitucional de una vulneración del principio de igualdad de sufragio sustanciada en una desviación de un $213 \%$. El Tribunal francés estimó que tal desviación era excesiva y «no conforme a la Constitución». V. SÁnchez Navarro A.J., Constitución, igualdad y proporcionalidad electoral, Centro de estudios políticos y constitucionales, 1998, p. 45. También SánCHEZ MuÑoz Ó., op. cit., pp. 508-511.

38 SÁNCHEZ MuÑoz Ó., op.cit., p. 513.

39 No hay, o no hemos encontrado, demasiada bibliografía al respecto. Destacan especialmente los excelentes trabajos que venimos citando de Sánchez Muñoz y Garrote Marcos, el Informe del Consejo de Estado y, especialmente para Francia, la obra citada de Sánchez Navarro. Una inmejorable panorámica del caso español, que incluye además una a nuestro juicio muy lúcida opinión sobre la STC 19/2011, se encontrará en Fernández Esquer, C. Y Montero, J. R., «El sistema electoral canario: representación proporcional y desigualdad de voto», en Pérez Sánchez, G. y Mújica Moreno, V., Textos para la reforma electoral de Canarias, Universidad de las Palmas de Gran Canaria, 2016, pp. 22-68.

40 Comisión de Venecia., Código de buenas prácticas en materia electoral. Directrices e informe explicativo. Aprobado por la Comisión en su 52 perído de sesiones (Venecia, 18 y 19 de octubre de 2002), Opinión nº 190/2002, p. 14.

41 Cita estas dos: «unidad administrativa con baja densidad demográfica pero de la misma importancia que otras que están representadas por lo menos por un diputado, o concentración de una minoría nacional específica». Téngase en cuenta que está hablando de circunstancias excepcionales con respecto a una media representativa «normal» (que es la que dota de contenido semántico al propio vocablo «excepción») propia del resto de circunscripciones. 
escala perfectamente creciente (o decreciente) de desigualdad de sufragio, una escala repetida de modo constitucionalmente obligado convocatoria tras convocatoria, y que torna muy difícil considerar que el «sufragio igual» del 68 se encuentre garantizado en sentido alguno.

El punto de partida remoto de esta comprensión europea — y democráticadel significado de la expresión «sufragio igual» ha situarse, por lo demás, en la Constitución de Weimar de 1919. El artículo 22 de la misma establecía que «los diputados serán elegidos por sufragio universal, igual, directo y secreto». Allí se inaugura una «interpretación maximalista» del sufragio igual, en contraste con la «interpretación restrictiva» anterior. Mientras con anterioridad a 1919 la expresión «voto igual» se entendía al modo decimonónico, tan solo en el sentido de prohibir el voto plural o reforzado — esto es, las dos grandes modalidades de la desigualdad en el número de votos-, tras Weimar se asume que la igualdad en el voto garantiza la igual incidencia de cada elector a la hora de decidir el resultado (sea este mayoritario o proporcional), y que, por tanto, no se puede permitir tampoco ninguna desigualdad en el valor del voto. Esta interpretación maximalista (hoy diríamos elemental) se generaliza, tal y como hemos puesto de manifiesto, tras la Segunda Guerra Mundial y es hoy moneda corriente en el constitucionalismo comparado ${ }^{42}$. Se basa en la distinción, ya explicitada, entre igualdad y proporcionalidad. La proporcionalidad (o la mayoría, o cualquier otro criterio decisional) es una opción entre muchas sobre cómo ha de tomar unas u otras decisiones colectivas la ciudadanía. La igualdad, sin embargo, es una decisión constitutiva sobre si, dado un determinado demos, puede permitirse que algunos ciudadanos tengan una influencia mayor que la de otros a la hora de tomar esas decisiones que afectarán a todos (se tomen como se tomen). Una igualdad que es, salvo casos muy estrictos, democráticamente sagrada.

¿Qué casos estrictos? A nuestro juicio solo dos. El primero es absolutamente excepcional, y remite a la idea de salus populi ${ }^{43}$. En determinadas situaciones cabe cancelar temporalmente las libertades democráticas, precisamente para poder salvarlas. Ese es el fundamento del Estado de Excepción que recogen las diferentes constituciones democráticas. El segundo es completamente habitual, y podemos remitirnos a él con el nombre de «federalismo». En buena parte de los Estados existentes hoy en día no hay un único demos perfectamente configurado, sino que conviven diferentes sensibilidades nacionales, étnicas, o de otro tipo. En tales casos - la realidad política es muchísimo más compleja que estos pobres brochazos que ofrezco aquí, pero espero que el amable lector sepa perdonarme-ciertas cámaras representativas se configuran de modo territorial, y en ellas carece de

42 Seguimos aquí a SÁnchez MuÑoz, op. cit, pp. 495-500. También Garrote de Marcos, op. cit. pp 263-265 y el Informe del Consejo de Estado, op. cit., pp. 160-164 describen esta evolución del significado de la expresión «sufragio igual».

43 Rafael Sánchez Ferlosio recordaba que «salus» no se traduce en esa expresión por «salud», sino por «salvación». En «la patria de papel», El País, 11/10/1980. 
sentido establecer que el voto de todos los ciudadanos del Estado (o de la Confederación, o de la Organización Internacional, etc.) sea igual, precisamente porque lo representado ahí no son los ciudadanos, sino colectivos de uno u otro tipo (naciones, estados federados, autonomías, minorías étnicas, etc.). No existen, a nuestro juicio, otros motivos que esos dos por los que pueda justificarse, en un estado democrático, lesionar la igualdad del voto de los ciudadanos a la hora de tomar decisiones que afectarán a todos por igual.

\section{PARADOJAS, APORÍAS, CONTRADICCIONES. EL SUFRAGIO IGUAL EN ESPAÑA}

Siendo ello así, la situación del sufragio igual en España es eminentemente paradójica. Tal derecho se halla recogido tanto en la Constitución como en pactos internacionales que nos vinculan jurídicamente. $\mathrm{Y}$, sin embargo, el sufragio no solo no es igual, sino que resulta ser uno de los más desiguales del mundo. ¿Cómo es posible esta paradoja? La respuesta se halla encerrada en las dos primeras entradas del artículo 68, que conviene citar en su literalidad:

El apartado primero del artículo 68 establece que «El Congreso se compone de un mínimo de 300 y un máximo de 400 Diputados, elegidos por sufragio universal, libre, igual, directo y secreto, en los términos que establezca la ley».

Por su parte, el apartado segundo señala que «La circunscripción electoral es la provincia. Las poblaciones de Ceuta y Melilla estarán representadas cada una de ellas por un Diputado. La ley distribuirá el número total de Diputados, asignando una representación mínima inicial a cada circunscripción y distribuyendo los demás en proporción a la población».

La segunda parte del artículo 68.1 — calcada, como en prácticamente todas las constituciones democráticas europeas posteriores a 1948, de la Constitución de Weimar- garantiza un conjunto de derechos de participación irrenunciables para la tradición democrática. El sufragio ha de ser universal, libre, directo y secreto. Y, desde luego, «igual», una garantía reconocida por todas las Teorías de la Democracia, que se justifica como el reverso de la igualdad que caracteriza a la ley: si ella es igual para todos, también todos habremos de ser iguales a la hora de elaborarla. El 68.2, sin embargo, no garantiza derechos. Lo que hace es (junto con el 68.3 y la primera parte del 68.1) articular un determinado sistema electoral. Se trata, como es sabido, de una circunstancia considerablemente extraña en el constitucionalismo comparado. Pero todavía más extraño, hasta desembocar en lo insólito, resulta el hecho de que, en la concreta articulación electoral que establece, se imposibilita de raíz el sufragio igual. Esto es: el sistema que establece niega el propio derecho estatuido antes.

En efecto. Según el 68.2 Soria ha de elegir al menos un diputado. Con los datos de población de 2019, si los sorianos eligen un escaño, entonces, para poder proporcionar al resto de los españoles que no viven en Soria (que son 46.634.380) 
un voto con un valor igual al otorgado a los sorianos, tales españoles habrían de elegir, por una sencilla regla de tres, 526 escaños. Pero el 68.1 lo imposibilita, puesto que establece un máximo de 400 escaños para los españoles. Así, el 68.1 garantiza un derecho que la combinación del 68.1 con el 68.2 impide.

Las principales líneas interpretativas que pueden encontrarse en la doctrina con respecto a esta extraña situación son a nuestro juicio tres. La primera consiste en interpretar la expresión «sufragio igual» del 68.1 como la mera exigencia de que cada ciudadano tenga solo un voto y no más. La igualdad vendría aquí referida exclusivamente al tertium «número de votos»: todos los sufragios, de cualquier español, son iguales en el sentido de que todos son igual a uno. Tal y como lo expresa Landelino Lavilla, «el voto es igual si todos y cada uno de los ciudadanos tiene derecho a uno y sólo a uno ${ }^{44}$. Una segunda perspectiva recurre a la tesis de las «modulaciones». Determinados derechos pueden, cuando entran en colisión con otros, matizarse en su aplicación práctica, en el sentido de que cabe admitir que no se reconozcan plenamente en ciertas circunstancias, precisamente para poder hacer realidad el otro u otros derechos con los que vendrían a resultar incompatibles ${ }^{45}$. Una última viene a reconocer una contradicción en la Constitución. Si se interpreta sufragio igual en el sentido de que el valor inicial del voto ha de ser idéntico, entonces existe una antinomia constitucional clara, puesto que la Norma Fundamental garantiza tal voto igual y, tras ello, lo imposibilita ${ }^{46}$.

La primera interpretación es a nuestro juicio la más endeble. Lo es, en primer lugar, semánticamente. Existe en castellano una expresión perfecta para ese matiz referencial que, bajo tal interpretación, se le supone al sufragio «igual». Si lo que el texto quisiera decir es que todos tenemos un voto y solo uno, parece lógico suponer que hubiera hablado de sufragio «único», en ningún caso «igual».

44 LAVILla Alsina L. Una bistoria para compartir: al cambio por la reforma (1976-1977), Galaxia Gutenberg, Barcelona, 2017, p. 237. Un desarrollo más extenso en Lavilla Alsina L.: «Condicionamientos del régimen parlamentario español consecuentes al sistema electoral», Teoría y Realidad Constitucional, 23, 2009, pp. 228-229.

45 Esta sería, al menos para el sistema electoral de Castilla-La Mancha, la interpretación de nuestro Tribunal Constitucional, a la luz de su sentencia 11/2019.

46 En expresión de Manuel Fraile «el propio artículo (68) es inconstitucional él mismo», en FRAILE M, «Los Sistemas Electorales», Reflexiones sobre el Régimen Electoral. IV Jornadas de Derecho Parlamentario, Congreso de los Diputados, Madrid, 1993, p. 517. Sánchez Navarro dedica un subcapítulo de su monografía a «La tesis de la inconstitucionalidad del régimen electoral vigente», que defienden no pocos autores. Si bien la cuestión ahí es la proporcionalidad, los argumentos son equiparables — con mayor pertinencia, de hecho- a la cuestión de la igualdad. SÁnchez Navarro A.J., op. cit., p. 78 y ss. De Cabo habla de las «contradicciones internas de la norma constitucional». De CABO A.: «Constitución, igualdad y proporcionalidad electoral», Revista Espanola De Derecho Constitucional, 1999, p. 309. Por lo demás, son legión las citas que — in llegar a la conclusión explícita de que en la constitución hay una contradicción- describen la situación en términos que no dejan mucho espacio a otra posibilidad. Valga por todas ellas, por la autoridad del órgano que la formula, esta: «Pese a las desigualdades existentes, el Tribunal Constitucional no ha tenido nunca ocasión de pronunciarse (...) La razón estriba, probablemente, en que los elementos determinantes de dichas desigualdades se encuentran contemplados en el artículo 68 de la Constitución». Informe del Consejo de Estado, op. cit., pp. 172-173, cursiva nuestra. 
Tampoco, en segundo lugar, parece permisible abrazar una hipótesis así desde un punto de vista bistórico y/o político. Interpretar la exigencia del sufragio «igual» como opuesta al voto plural o reforzado pudo tener sentido a principios del siglo $\mathrm{XX}$. Eran tiempos en los que se asumía con total naturalidad que ni las mujeres ni los trabajadores manuales tenían derecho al voto y en los que se escuchaban todavía múltiples defensas del sufragio restringido o censitario. Y eso, por descontado, tan sólo en los escasísimos sistemas parlamentarios existentes en el mundo. En esa atmósfera moral pudo tener sentido interpretar el sufragio igual como exigencia de un solo voto. Pero tal atmósfera empezó a diluirse en Weimar, desapareciendo definitivamente tras la Segunda Guerra Mundial. Considerar que en la España de 1978 tanto los políticos que redactaron el texto de la Constitución como los ciudadanos que la votaron estaban pensando en impedir que unos ciudadanos (¿los ricos?, ¿los nobles?) tuvieran más votos que otros no parece demasiado verosímil ${ }^{47}$.

Con respecto a tesis de las modulaciones conviene iniciar su análisis señalando que ya su mera formulación presupone el rechazo de la primera interpretación. En efecto, si el sufragio igual fuera equivalente al voto único no haría falta modular ni matizar nada, puesto que la igualdad en el voto se hallaría en tal caso plenamente garantizada. Así, parece claro que lo que se modula sólo puede ser el valor del voto que la ley — la propia Constitución, en este caso- concede a cada ciudadano. Pero, siendo ello así, todo indica que la propia tesis de las modulaciones no es, en realidad, por debajo de su apariencia lingüística, otra cosa que la tercera línea interpretativa, esto es, la de la contradicción. En efecto, si nos atenemos a la literalidad de tal tesis, la Constitución, en el 68.1, garantizaría un «sufragio igual» para, a renglón seguido, en el 68.2, «modularlo» o «matizarlo» de un modo tal que queda forzosamente configurado en nada menos que 52 grupos de diferente valor de voto, que mantienen entre sí desigualdades que alcanzan, en sus extremos, valores de cuatro votos concedidos a ciertos ciudadanos y uno a otros. Pero a la vista está que tal cosa no es una modulación de un sufragio igual inicialmente garantizado, sino la directa e inevitable concesión de un sufragio desigual por parte del propio texto constitucional. La modulación de un sufragio igual parece presuponer, en su desnuda formulación, una composición de lugar según la cual se concede un voto igual que luego, de acuerdo a unas u otras justificaciones que habrán fundamentarse de modo objetivo y razonado, se matiza o gradúa de acuerdo a esas mismas razones que la propia justificación ha de proveer a posteriori y solo en ciertas coyunturas. Pero lo que la Constitución, en su mero despliegue textual, ordena con respecto al sufragio de los españoles no es un estado de cosas ni remotamente parecido, puesto que obliga siempre y en todo

47 Esta argumentación se despliega, por lo demás, sin salirse de la tesis interpretativa del originalismo, e incluso desde la misma — a nuestro juicio muy limitada - resulta válida. Por descontado, si se asume la perspectiva de lo que significa una Constitución viva, la interpretación decimonónica se torna inconcebible. V. ACKerman B.: «The living constitution», Harvard Law Review, 120, 2006. 
caso, cada cuatro años, en cada convocatoria electoral, quiérase o no, a que el valor de voto de voto de los titulares de la soberanía sea desigual. Y lo ordena justo después de afirmar que tal sufragio será «igual». No parece, por tanto, que se module un sufragio igual a todos concedido en un primer momento, sino, más bien, que a todos se concede, desde tal primer momento, un sufragio con desigual valor, y ello a pesar la afirmación precedente de la igualdad de tal sufragio, de la que no cabe decir que se modula en ningún aspecto, puesto que jamás ha existido como entidad siguiera modulable: si se siguen los preceptos constitucionales del 68.2, la igualdad de sufragio del 68.1 deja de existir o, si se quiere, ha existido tan solo como mera enunciación lingüística sin valor normativo alguno. No es que se module, es que no existe.

Supongamos una madre que les dice a sus dos hijas gemelas: «os voy a dar una paga semanal igual, pero la voy a modular: cada sábado, 5 euros a María y 20 a Eva. Todos los sábados, hasta que tengáis edad de trabajar». Algo muy parecido es lo que, a la postre, hace nuestra constitución con el voto de los españoles. Cabe aducir que la madre puede tener, sin duda, buenas razones para premiar a Eva y penar a María. Pero, si las tiene, es evidente que, en su decisión, las ha esencializado, esto es, las ha dado por indubitables e indelebles en la substancia misma de una y otra hija, las ha asumido como indistinguibles de su naturaleza, asignándoselas de una vez y para siempre, como parte de su ser. Una decisión que, en lenguaje jurídico, vendría a traducirse como que ha constitucionalizado tales razones. Así, tal madre asume que Eva, por su propia constitución - moral o de otra índole- merece siempre, constitutivamente, 20 euros; mientras que María, por idénticas razones, merece 5 . Con independencia de la consistencia de tales razones, es el mero hecho de que las constitucionalice en su decisión lo que torna imposible, para tal madre, que afirme a la hora de enunciar la misma que la paga que les concede es «igual». Una cosa es que tenga razón o que su decisión esté justificada, otra muy diferente es que pueda saltar por encima del principio de no contradicción al enunciarla lingüísticamente. De la misma manera, si se quisiera justificar o encontrar razones por las que la Constitución constitucionaliza el voto desigual, se habría de descender a explicar que, en efecto, de la consideración de tales razones se desprende que los madrileños merecen un voto mientras que, sin embargo, los zamoranos merecen tres, y que eso es constitucionalmente permisible. Pero, y este es el quid aquí, eso ni siquiera rozaría la tesis de la desigualdad del voto de unos y de otros, tesis que tan solo vendría en todo caso a justificar, en ningún caso a refutar ${ }^{48}$.

48 López Guerra, por ejemplo, ha señalado, como justificación de la desigualdad del voto, que gracias a la misma se lograrían «objetivos necesarios para la comunidad política, como, entre otros, el de colocar en una posición de igualdad efectiva a los electores de zonas desfavorecidas, condenados, de otra forma, a encontrarse permanentemente sin medios de hacer oír su voz en las asambleas parlamentarias». LóPEZ GUERRA, L. «Introducción al Derecho Constitucional», Tirant, Valencia, 1994, p. 147, citado en: Reviriego, F., «Las reformas electorales y la magnitud de las circunscripciones», Estudios de Deusto, 63, 2015, 189-221, p. 201. 
La naturaleza de las razones que se pueden deslizar al respecto ofrece, por lo demás, otro flanco argumentativo que viene a reforzar, de nuevo, la tesis de la contradicción. Es evidente que, en la medida en que el criterio mediante el que se desiguala el voto en nuestra Constitución es territorial, pues se sustancia en la circunstancia de hallarse uno censado en tal o cual provincia - una circunstancia que en ocasiones será social, pero que en la inmensa mayoría de los casos viene originada por el mero nacimiento en uno u otro lugar - las únicas razones que podrían venir a legitimar tal desigualación habrían de radicarse en lo que antes hemos denominado perspectiva federal. Así, podría alegarse que el voto es desigual debido a que se atiende a la necesidad de representar de una u otra manera las diferentes entidades territoriales que, precisamente por su necesidad constitutiva de verse representadas en cuanto tales, se configuran como circunscripciones electorales. Y que, en la medida en que la Constitución asume esa necesidad constitutiva en su interior, eso choca con el voto igual y lo modula ${ }^{49}$.

Pero el caso es que, precisamente en la medida en que la Constitución reconozca atender a tales razones territoriales, no puede modular ningún voto igual, sino tan solo anularlo. Si un sistema electoral ha de representar territorios, entonces no puede pretenderse que, además, garantice el «sufragio igual». Esa pretensión es en sí misma contradictoria, ya que el sufragio igual es un derecho individual del ciudadano, no de los territorios. Por eso en el constitucionalismo comparado las diferentes regulaciones electorales de aquellas cámaras que persiguen representar territorios no incluyen la expresión «sufragio igual» en su articulado $^{50}$. No lo hacen porque se trata de una garantía jurídica evidentemente incompatible con el tipo de representación que vienen a sustanciar. Una práctica jurídica que se recoge tanto en las diferentes regulaciones electorales territoriales internacionales como, paradójicamente, en las que alberga nuestra propia Constitución.

Pero a la vista está que, con independencia de su mayor o menor pertinencia, esa misma justificación implica de modo inevitable que el voto no es igual.

49 Esa es, de hecho, la tesis que el Tribunal Constitucional maneja en su sentencia 19/2011. Ahí establece que la «desviación o corrección del principio de igualdad en el sufragio encuentra su justificación en el mandato constitucional y estatutario de que el sistema electoral además de proporcional ha de asegurar la representación de las diversas zonas del territorio» (FJ10). Esto es: se modula el voto igual para poder atender a la representación de los territorios.

50 En Alemania la constitución federal garantiza el sufragio igual para el Bundesbag (art. 38.1), pero no para el Bundesrat (arts. 50-53). Austria garantiza el sufragio igual para su cámara baja (art. 26), pero no para la alta (arts. 34 a 37). En Estados Unidos, el voto igual de las elecciones al Congreso se garantiza desde Baker vs. Carr a través de la Decimocuarta enmienda, que sin embargo carece de aplicación —en ese sentido electoral - para el sufragio al Senado, que es evidentemente desigual. La Comisión de Venecia recoge muy bien esta dinámica, por lo demás tautológica, cuando señala que «la igualdad de poder de voto deberá aplicarse por lo menos a las elecciones a las cámaras bajas del Parlamento y a las elecciones regionales y locales». Comisión de Venecia, op. cit., p. 6. Como resulta obvio, el sufragio igual — que es por definición igual para cada ciudadano individual — no puede exigirse de las Cámaras representativas articuladas de modo territorial. 
La Norma Fundamental se ocupa de la regulación electoral de cuatro tipos de cámaras representativas: el Congreso, el Senado, las Cámaras legislativas autonómicas y los consistorios municipales. El Senado es una cámara territorial, y por eso en su regulación la expresión sufragio «igual», aunque aparece, lo hace recogida explícitamente tan solo «en cada provincia», no para todos los ciudadanos españoles, pues tal extremo que se revelaría imposible. Con respecto a las cámaras autonómicas, el 152. 1 establece de cada una de ellas que habrá de ser «elegida por sufragio universal, con arreglo a un sistema de representación proporcional que asegure, además, la representación de las diversas zonas del territorio». Esto es, incluye la representación territorial. Precisamente por ello, no puede citar el sufragio igual, como en efecto no hace. En cuanto a los municipios, el artículo 140 señala que «los Concejales serán elegidos por los vecinos del municipio mediante sufragio universal, igual, libre, directo y secreto, en la forma establecida por la ley». Se garantiza, por tanto, el sufragio igual, pero está ausente cualquier indicio de representación territorial.

Es decir, que cuando tanto en el derecho comparado como en el articulado constitucional —excepción hecha de la regulación del Congreso de los Diputados- se articula la representación de los ciudadanos, el sufragio igual deviene una garantía democrática sine qua non que ha de ser protegida frente a cualquier ocurrencia del legislador. Pero, por contra, cuando de lo que se trata es de representar territorios tal garantía no se incluye, pues no solo carecería de sentido en tal contexto, sino que resultaría contradictoria con el objeto de la representación ${ }^{51}$. Una práctica jurídica cuya evidente consistencia queda, sin embargo, hecha añicos en el artículo 68, pues ahí esas dos lógicas representativas se mezclan de modo contradictorio. Se incluye una mención al sufragio igual, que queda así configurado como un derecho de todos los españoles y, a continuación, se articula un sistema electoral territorialmente sustanciado que frustra de modo inmediato e inevitable la igualdad en el voto, que por tanto no ha existido jamás más que como letra muerta y voz vacía. Nunca, desde 1978, hemos tenido los españoles un sufragio igual para elegir al Congreso de los Diputados.

¿Es esa, bajo esta Constitución, una consecuencia práctica ineluctable? Al menos a nuestro juicio, no. Alguna vez se ha tildado la situación de «aporética». Pero lo que el artículo 68 encierra no es tanto una aporía —un lugar sin salidacomo una contradicción. Y una contradicción no es un espacio cerrado sobre sí

51 Esta es sin duda la razón del posicionamiento del TEDH con respecto al voto igual, ya que en muchos estados europeos no existen dos cámaras y, en consecuencia, la representación ciudadana y la territorial se mezclan en una misma institución representativa. Si el Tribunal llevara hasta las últimas consecuencias la igualdad de sufragio, se vería abocado a modificar el propio ordenamiento constitucional de tales estados. V. Alberdi M.R.P., «La delimitación del derecho de sufragio activo por el Tribunal Europeo de Derechos Humanos», Revista De Derecho Politico, 1, 2013; y FERNÁNDEZ ESQUER C., «Un apunte sobre la jurisprudencia del Tribunal Europeo de Derechos Humanos en materia de sistemas electorales», Revista de Derecho Electoral, $25,2018$. 
mismo y carente de aperturas, sino una situación con dos salidas que no pueden tomarse a la vez, y que por tanto obligan a elegir. Una de las dos posibilidades que la constitución alumbra ha de incumplirse necesariamente. Hasta ahora se ha optado por una posibilidad: sacrificar el derecho democrático y garantizar el sistema circunscripcional. Pero la otra solución es igualmente constitucional (si es que no es, por muchos motivos, más, muchísimo más acorde con la Constitución, de hecho). Qué tiene que ocurrir para que, de las dos opciones que nuestra Norma Fundamental alberga, sea la igualitaria $-\mathrm{y}$ no la provincial — la que se imponga, y cómo sería política o judicialmente posible alcanzar tal empresa es por desgracia una cuestión que cae por completo fuera de los márgenes del presente texto.

TITLE: A constitutional antinomy? (Un)equal suffrage in the constitution of 1978.

ABSTRACT: The article examines the legal and political state of equal suffrage in Spain. The perspectives applied are fundamentally those of three well-differentiated subject areas: Political Philosophy, Constitutional Law and Political Science. In addition, the text also grounds on a more younger field, the Voting Theory. The conclusions reached are highly worrying: not only that Spain is the country with one of the highest verifiable incidence of inequality in its voting system, but also that its Constitution of 1978 is host to a legal antinomy that has impeded adequate constitutional protection to guarantee the fundamental right of its citizens to an equal vote.

Resumen: Se aborda la peculiar situación jurídico-politica del sufragio igual en nuestro país. Las perspectivas que se utilizan son sobre todo las propias de tres disciplinas bien diferenciadas: la Filosofía Política, el Derecho Constitucional y la Ciencia Política. A ellas se une, además, el enfoque propio de una rama del conocimiento más joven y menos frecuentada, la Teoría de las Votaciones. Las conclusiones son considerablemente preocupantes: por un lado, empíricamente, España es uno de los países del mundo con una mayor desigualdad de voto; por otro, jurídicamente, la constitución de 1978 se encuentra presa de una antinomia que ba impedido que el derecho fundamental de los ciudadanos al voto igual pueda ser protegido constitucionalmente.

KEY WORDS: Political representation - Equal vote - Constitutional antinomy - Electoral system Bicameralism - Philosophy of Law - Political Philosophy - Theory of democracy - Theory of Voting .

Palabras Clave: Representación política - Voto igual - Antinomia constitucional - Sistema electoral - Bicameralismo - Filosofía del Derecho - Filosofía Política - Teoría de la democracia - Teoría de las votaciones.

FECHA DE RECEPCIÓN: 27.02.2019 FeCHA DE ACEPTACIÓN: 19.02.2020 